\title{
High mortality rates after radical cystectomy: we must have acceptable protocols and consider the rationale of cutaneous ureterostomy for high-risk patients
}

\author{
Fernando Korkes ${ }^{1}$, Juan Palou ${ }^{2}$ \\ ${ }^{1}$ Disciplina de Urologia, Faculdade de Medicina do ABC, Santo André, SP, Brasil; ${ }^{2}$ Fundacion Puigvert \\ Universitat Autonoma de Barcelona, Espanha
}

Bladder cancer is a common disease, and for T2-T4 stages, radical cystectomy is the first treatment option (1). An interesting Swedish study has evaluated the natural history of urothelial bladder cancer. After 6 months of diagnosis, 38\% of patients develop metastasis if untreated (2). Five-year Cancer-specific survival is as low as 14\% in such scenery, and overall survival is only 5\% (2). On the other hand, if treated these patients have a 5 -year CSS and OS of 60\% and 48\% respectively (2). Radical cystectomy is, therefore, the first option, as it is also stated by the EAU, NCCN, AUA / ASCO / ASTRO / SUO guidelines/consensus (3-5) is associated with a significant survival gain in comparison to observation (2), to multiple resections, chemotherapy or radiotherapy (6). In patients with stage II disease, cystectomy is associated with a three-fold increase in survival, increasing mean overall survival from 16 to 45 months (6). In a SEER study evaluating 328,560 patients, radical cystectomy and chemotherapy were the only factors associated with improvements in survival (7). Trimodal "bladder-sparing" approaches that combine maximal transurethral resection, chemotherapy, and radiotherapy or neoadjuvant chemotherapy with partial cystectomy are an option but only for a small percentage of patients (3).

However, if we analyze data carefully, the guideline recommendations are rarely followed.
In a SEER study that evaluated 6.737 patients in the USA with stage II disease (non-metastatic, muscle-invasive bladder cancer), only $8.3 \%$ underwent radical cystectomy (8). The odds of an octogenarian to undergo radical cystectomy in the USA is five-times lower than a young patient (8). Hispanic origin, Afro-American origin, and lower scholar level patients are also less treated properly when they have muscle-invasive bladder cancer (8). According to a very interesting study that evaluated 27,578 patients from the SEER, only 6\% of patients with muscle-invasive bladder cancer (pT2-pT4) in the USA underwent radical cystectomy between 2007 and 2013 (8). Less than 19\% of patients with pT2 disease in the USA undergo radical cystectomy (9).

And why does this happen? The answer is because radical cystectomy is associated with high morbidity and mortality rates. When described in the late 1940s, radical cystectomy was associated with a perioperative mortality of 33\% (10). In the 1970 s perioperative mortality decreased to $11 \%$ (and remained around 2.1\% to $4.7 \%$ after the 1980s) (11). Analyzing mortality after radical cystectomy is a slippery slope, as demonstrated in Table-1. Studies report distinctive data. In-hospital mortality is lower than 30-day mortality, which is two to three-fold lower than 90-day mortality. And these numbers vary widely $(1,12,13)$. 
Table 1 - Mortality after radical cystectomy in distinctive settings.

\begin{tabular}{lccccc}
\hline Author & N & IHM & 30-day & 90-day & Setting \\
\hline Barbieri, 2019, (14) & 6,728 & $0.54 \%$ & - & - & Large volume academic centers \\
Udovicich, 2017. (15) & 803 & $2.2 \%$ & - & - & $\begin{array}{c}\text { Victoria state, Australia } \\
\text { English database }\end{array}$ \\
Afshar, 2018, (12) & 15,292 & & $2.7 \%$ & $7 \%$ & $\begin{array}{c}\text { English database (after } \\
\text { Afshar, 2018, (19) }\end{array}$ \\
& & & $1.5 \%$ & $4 \%$ & centralization program) \\
Waingankar, 2019, (1) & 47,028 & & $3.0 \%$ & $8.2 \%$ & SEER, USA \\
Dell'Oglio, 2019, (16) & 7,076 & - & - & $10.7 \%$ & SEER, USA \\
Timote0, 2019, (18) & 5.097 & $7.38 \%$ & - & - & DATASUS, Brasil \\
DATASUS, 2019 & 1,377 & $8.5 \%$ & - & - & DATASUS, state of SP \\
DATASUS, 2019 & 161 & $8.1 \%$ & - & & DATASUS, institution 1, São Paulo \\
DATASUS, 2019 & 84 & $6.0 \%$ & - & & DATASUS, institution 2, São Paulo \\
DATASUS, 2019 & 71 & $11.3 \%$ & - & & DATASUS, institution 3, São Paulo \\
DATASUS, 2019 & 53 & $15.9 \%$ & - & & DATASUS, institution 4, São Paulo \\
DATASUS, 2019 & 81 & $14.8 \%$ & - & & DATASUS, suburban institutions \\
& & & & & of São Paulo \\
\hline
\end{tabular}

IHM = in-hospital mortality

In large volume academic referral centers in the USA, in-hospital mortality after 6,728 cystectomies was as low as $0.54 \%$ (14). This results are impressive, and can be either effect of experience but also to a high selection bias. If we go to other less selected settings, things start to change. An Australian epidemiologic study has observed a 2.2\% rate after 803 surgeries (15). A British study evaluated 15,292 patients and have observed a mortality rate of 2.7\% after 30 days and of 7\% after 90 months (12). In a large epidemiologic study evaluating SEER data, the mortality rate of 47,028 patients who underwent radical cystectomy in 1,162 centers was 3\% after 30 days and 8.2\% after 90 days (1). In another large SEER study with 7,076 patients, 90-day mortality ranged from $10.75 \%$ to $13.1 \%$ (16). In Spain a national database study that has evaluated 7,999 patients found a 4.7\% in-hospital mortality and 6.2\% 90day mortality rate (17).

In developing countries, reality seems to be much tougher in the public scenario. We have recently published a study demonstrating a 7.38\% in-hospital mortality rate, with a wide variation according to geographic regions, varying from $6.2 \%$ in the south to $28.6 \%$ in certain regions of the North of Brazil (18). Data from the public health system (DATASUS) in the State of São Paulo, the most populated and wealthier state of Brazil, between 2008-2018 demonstrated amid 1,377 radical cystectomies reported, and 117 in-hospital deaths (8.5\%). In the five largest academic institutions in the city of São Paulo that treat exclusively patients from the public health system, in-hospital mortality varied from $6.0 \%$ to $15.9 \%$ (18). And it is important to state that these numbers represent in-hospital mortality. Probably 90-day mortality is even higher.

Ureterostomy as a strategy to reduce mortality? Even though the AUA / ASCO / ASTRO / SUO guidelines recommend as first-line treatment for MIBC not only radical cystectomy but also urinary diversion using intestinal segments (ileal conduit, continent cutaneous diversion or orthotopic neobladder) as standard treatments (4), this is not what is currently done in more than $90 \%$ of patients with MIBC in the USA, where only a fraction of patients with MIBC undergo radical cystectomy. Data evaluating a series of patients undergoing radical cystectomy in developing countries are scarce in the literature, mainly because mortality rates are 
unacceptable in most public large volume centers. Some key points that have been adopted by $\mathrm{Eu}$ ropean centers might urgently be adopted in the developing world (3). They include centralization of treatment and surgeries to referral centers (19, 20), proper patient preparation and adequate choice of diversion for each patient $(12,21)$. In high risk patients, cutaneous ureterostomy might be also considered as a good alternative $(3,22)$. Several authors have demonstrated a significant reduction in complications and mortality with cutaneous ureterostomy after radical cystectomy mainly in patients with high risk for complications; it reduces the duration of the surgery and all the complications related to bowel manipulation, thus decreasing the risk of mortality in patients with comorbidities (22-25).

Some key-points are that not every patient with MIBC is a candidate for radical cystectomy, but also not every patient suitable for radical cystectomy is a candidate for urinary diversion with intestinal segments. Urinary diversion using intestinal segments is responsible for a large number of these deaths (23). Even though this insight has been widely published before (22-25), mortality rates at many Centers are still high. If in one hand we discuss robotic use $(21,26-28)$ that is been used in the vast majority of patients treated with muscle-invasive bladder cancer, we have to talk about this problem in our journals, meetings, boards, and discussions and bring better solutions to be sure that we are first of all not harming our patients. We have to properly perform a correct pre/intra/postop management of the patients and therapeutic decisions might be in accordance to comorbidities and life expectancy.

\section{REFERENCES}

1. Waingankar N, Mallin K, Egleston BL, Winchester DP, Uzzo RG, Kutikov A, et al. Trends in Regionalization of Care and Mortality For Patients Treated With Radical Cystectomy. Med Care. 2019;57:728-33.

2. Martini A, Sfakianos JP, Renström-Koskela L, Mortezavi A, Falagario UG, Egevad L, et al. The natural history of untreated muscle-invasive bladder cancer. BJU Int. 2019. [Epub ahead of print]
3. Faba OR, Tyson MD, Artibani W, Bochner BH, Burkhard F, Gilbert SM, et al. Update of the ICUD-SIU International Consultation on Bladder Cancer 2018: urinary diversion. World J Urol. 2019;37:85-93.

4. Statements $G$ and Evaluation IP: American Society for Radiation Oncology (ASTRO)/Society of Urologic Oncology (SUO) BLADDER CANCER : AUA/ASCO/ASTRO/SUO American Urological Association (AUA)/American Society of Clinical Muscle-Invasive Oncology (ASCO)/American Society. 2017: 1-42.

5. Alfred Witjes J, Lebret T, Compérat EM, Cowan NC, De Santis M, Bruins HM, et al. Updated 2016 EAU Guidelines on Muscleinvasive and Metastatic Bladder Cancer. Eur Urol. 2017;71:46275.

6. Gild P, Nguyen DD, Fletcher SA, Cole AP, Lipsitz SR, Kibel AS, et al. Contemporary Survival Rates for Muscle-Invasive Bladder Cancer Treated With Definitive or Non-Definitive Therapy. Clin Genitourin Cancer. 2019;17:e488-e93.

7. Weiner AB, Keeter MK, Manjunath A, Meeks JJ. Discrepancies in staging, treatment, and delays to treatment may explain disparities in bladder cancer outcomes: An update from the National Cancer Data Base (2004-2013). Urol Oncol. 2018;36:237.e9-237.e17.

8. Williams SB, Huo J, Kosarek CD, Chamie K, Rogers SO Jr, Williams MA, et al. Population-based assessment of racial/ ethnic differences in utilization of radical cystectomy for patients diagnosed with bladder cancer. Cancer Causes Control. 2017;28:755-66.

9. Williams SB, Huo J, Chamie K, Hu JC, Giordano SH, Hoffman $\mathrm{KE}$, et al. Underutilization of Radical Cystectomy Among Patients Diagnosed with Clinical Stage T2 Muscle-invasive Bladder Cancer. Eur Urol Focus. 2017;3:258-64.

10. Jewett HJ, Lewis EL. Infiltrating carcinoma of the bladder; curability by total cystectomy. J Urol. 1948;60:107-18.

11. Hendry WF. Morbidity and mortality of radical cystectomy (1971-78 and 1978-85). J R Soc Med. 1986;79:395-400.

12. Afshar M, Goodfellow H, Jackson-Spence F, Evison F, Parkin J, Bryan RT, et al. Centralisation of radical cystectomies for bladder cancer in England, a decade on from the 'Improving Outcomes Guidance': the case for super centralisation. BJU Int. 2018;121:217-24.

13. Corradi RB, Galvao GJ, Oliveira GM, Carneiro VF, Miconi WG, Salles PG, et al. Radical cystectomy with pelvic lymphadenectomy: pathologic, operative and morbidity outcomes in a Brazilian cohort. Int Braz J Urol. 2016;42:431-7.

14. Barbieri CE, Lee B, Cookson MS, Bingham J, Clark PE, Smith $\mathrm{JA} \mathrm{Jr}$, et al. Association of procedure volume with radical cystectomy outcomes in a nationwide database. J Urol 2007;178(4 Pt 1):1418-21.

15. Udovicich C, Perera M, Huq M, Wong LM, Lenaghan D. Hospital volume and perioperative outcomes for radical cystectomy: a population study. BJU Int. 2017;119(Suppl 5):26-32. 
16. Dell'Oglio P, Tian Z, Leyh-Bannurah SR, Larcher A Mazzone E, Moschini M, et al. Development of a New Comorbidity Assessment Tool for Specific Prediction of Perioperative Mortality in Contemporary Patients Treated with Radical Cystectomy. Ann Surg Oncol. 2019;26:19429.

17. Llorente C, López B, Hernández V, Guijarro A, PérezFernández E. Variability in complications and operative mortality after radical cystectomy in Spain. Actas Urol Esp. 2017;41:32-8.

18. Timoteo F, Korkes F, Baccaglini W, et al: BLADDER CANCER TRENDS AND MORTALITY IN THE BRAZILIAN PUBLIC HEALTH SYSTEM Title. Int Braz J Urol 2019; xXX: $\mathrm{XXX}$.

19. Afshar M, Goodfellow H, Jackson-Spence F, Evison F, Parkin J, Bryan RT, et al. Centralisation of radical cystectomies for bladder cancer in England, a decade on from the 'Improving Outcomes Guidance': the case for super centralisation. BJU Int. 2018;121:217-24.

20. Seisen T. Examining the role of centralisation of radical cystectomy for bladder cancer. BJU Int. 2018;121:165-7.

21. Hussein AA, Elsayed AS, Aldhaam NA, Jing Z, Osei J, Kaouk J, et al. Comparison of Long-Term Oncologic Outcomes among Historical Open and Minimally Invasive Retrospective Studies. J Urol. 2019: [Epub ahead of print]
22. Nogueira L, Reis RB, Machado RD, Tobias-Machado M, Carvalhal G, Freitas C Jr, et al. Cutaneous ureterostomy with definitive ureteral stent as urinary diversion option in unfit patients after radical cystectomy. Acta Cir Bras. 2013;28(Suppl 1):43-7.

23. Meng YS, Wang Y, Fan Y, Su Y, Liu ZH, Yu W, et al. Impact of different surgical methods of radical cystectomy on the perioperative complications in patients over 75 years. Beijing Da Xue Xue Bao Yi Xue Ban. 2016;48:632-7.

24. Longo N, Imbimbo C, Fusco F, Ficarra V, Mangiapia F, Di Lorenzo $G$, et al. Complications and quality of life in elderly patients with several comorbidities undergoing cutaneous ureterostomy with single stoma or ileal conduit after radical cystectomy. BJU Int. 2016;118:521-6.

25. Burkhard FC, Wuethrich PY. Cutaneous ureterostomy: 'back to the future'. BJU Int. 2016;118:493-4.

26. Dal Moro F, Haber GP, Wiklund P, Canda AE, Balbay MD, Stenzl A, et al. Robotic intracorporeal urinary diversion: practical review of current surgical techniques. Minerva Urol Nefrol. 2017;69:14-25.

27. Tyritzis SI, Gaya JM, Wallestedt-Lantz A, Pini G, Everaerts W, de Naeyer $G$, et al. Current role of robotic bladder cancer surgery. Minerva Urol Nefrol. 2019;71:301-308.

28. Gaya JM, Vila-Reyes H, Gavrilov P, Territo A, Breda A, Palou J. Roboticvradical cystectomy. Arch Esp Urol. 2019;72:293-298.
Fernando Korkes, MD

Departamento de Urologia

Faculdade de Medicina do ABC

Santo André, SP, Brasil,

E-mail: fkorkes@gmail.com
ARTICLE INFO

Fernando Korkes

http://orcid.org/0000-0003-4261-4345

Int Braz J Urol. 2019; 45: 1090-3 